\title{
Quando Clio encontra Hermafrodito e Tirésias, mas Narciso está no caminho: Reflexões a partir de história oral em minis- térios de "cura" de travestis
}

\section{When Clio find Hermaphrodite and Tiresias, but Narciso is on the way: Reflections from oral history in ministries of "healing" of transvestites}

Eduardo Meinberg de Albuquerque Maranhão Filho*

Resumo: Apresento, neste texto, algumas reflexões epistemológicas / teóricas / metodológicas acerca dos desafios e riscos de uma pesquisa feita por quem é pesquisadorx e ao mesmo tempo, nativx da pesquisa. Este artigo se fundamenta em minha tese de doutorado, em que pesquisei, através de etnografia e história oral, o que pessoas transgêneras, ex-transgêneras e em outras situações nãocisgêneras faziam com o que determinados discursos religiosos (principalmente de igrejas inclusivas e de missões de "cura e libertação" de travestis faziam (ou procuravam fazer) delas.

Palavras-chave: história oral e etnografia; "cura e libertação" de travestis; gênero e religião

* Presidente da Associação Brasileira de História das Religiões (ABHR). Pós-Doutor em Ciências Humanas pelo Programa Interdisciplinar da Universidade Federal de Santa Catarina (UFSC). Pós-Doutorando Júnior em História pela UFSC (Bolsista CNPq - Brasil). Doutor em História Social pela Universidade de São Paulo (USP). Mestre em História do Tempo Presente pela Universidade do Estado de Santa Catarina (UDESC). Graduado em História pela USP. 
Pesquisador do Laboratório de Estudos de Gênero e História (LEGH/UFSC). Bolsista CAPES à época da pesquisa que originou este texto. E-mail: edumeinberg@gmail.com

\begin{abstract}
I present, in this text, some epistemological / theoretical / methodological reflections about the challenges and risks of a research made by who is a researcher and at the same time, native. This article is based on my doctoral thesis, where googled through ethnography and oral history, what transgender people, former transgendered people and other non-cisgender situations made with certain religious discourses (mainly inclusive churches and missions of "healing and deliverance" of transvestites did (or tried to) them.
\end{abstract}

Keywords: oral history and ethnography; "healing and deliverance" of transvestites; gender and religion.

Quando eu te encarei frente a frente não vi o meu rosto Chamei de mau gosto o que vi, de mau gosto o mau gosto

É que Narciso acha feio o que não é espelho

Caetano Veloso

Tô iluminado pra poder cegar, tô ficando cego pra poder guiar

Tom Zé

\title{
Introdução
}

Apresento aqui, com base em minha pesquisa de doutorado, ${ }^{1}$ algumas reflexões acerca dos desafios epistemológicos / teóricos / metodológicos de quem realiza um campo de pesquisa em que é, de algumas formas, nativx. ${ }^{2}$

Este texto encontra-se dividido da seguinte forma: primeiramente, e estimulade $^{3}$ pelo tema deste dossiê, aludo a personagens mitológicos gregos para falar de pessoas historiadoras (sobretudo as que fazem história oral) e de algumas das pessoas que colaboraram com minha tese de doutorado: pessoas transgêneras, ${ }^{4}$ ex-transgêneras,${ }^{5}$ ex-ex-transgêneras ${ }^{6}$ e em outras situações não-cisgêneras. ${ }^{7}$ Em seguida, reflito alguns dos desafios e riscos no espelho da pesquisa que realizei, que pode ser considerada narcísica. Ao final deste trajeto inconclusivo e quase carontiano $^{8}$, faço algumas considerações e provoca-ações a reflexões. 


\section{Entre Clio, Hermafrodito e Tirésias - e com Narciso por perto}

Tendo ciência do instigante tema deste dossiê da Esboços, intitulado Quando Clio encontra as "sexualidades disparatadas": História e experiências de LGBTs, minha primeira questão foi: como Clio, a musa da História, se relaciona com gente de carne e osso - ou como nós, pessoas "da História" (supostamente arautos da musa), pesquisamos a história das outras pessoas, e quais as relações assimétricas e hierárquicas (des)envolvidas? Um movimento eólico $o^{9}$ de indagações se avizinhava: quem tem o protagonismo das (sobre as) histórias contadas e biografias alheias? somos nós quem devemos supostamente "dar voz" (como se costuma dizer) ou "dar ouvidos" a estas pessoas? quais as relações em campo entre pesquisadorxs e pesquisadxs? seriamos nós também pesquisadxs por quem pesquisamos? ${ }^{10}$ quais as táticas metodológicas mais convenientes para um trabalho ético? devemos guiar nosso campo ou sermos guiadxs pelo mesmo? nossa subjetividade pode tomar as rédeas do trabalho, e em caso positivo, até que ponto? podemos nos furtar de pensar os fracassos e desafios de pesquisa? O quanto arrepios, choros e (des)afetos nos moldam, e afetam quem pesquisamos? em um trabalho de história oral no tempo imediato, ${ }^{11}$ como devemos tratar nossxs entrevistadxs? seriam elxs "depoentes", "testemunhos" a serem "investigados" - usando aqui termos bastante policialescos? ou seriam colaboradorxs, parceirxs, e em alguns casos, quase co-autorxs? é a mesma coisa pesquisar alguém que entendemos ser "vítima" e alguém que cremos ser "perpetradorx" de violência? quais os limites e fronteiras entre o que podemos considerar dicotômica e binariamente "vítima" e "perpetradorx"? ${ }^{12}$ há alguma neutralidade em nosso trabalho, afinal? como operarmos hermenêuticas ${ }^{13}$ sobre nós mesmxs e sobre quem pesquisamos? quando pesquisamos nos pesquisamos também? Longe de responder a todas as inquietações que vieram à mente ao saber do tema deste dossiê, procurarei sinalizar para o último dos pontos acima elencados: a questão de nossos trabalhos serem, muitas vezes, possíveis espelhos de nós mesmxs.

Antes de continuarmos, é necessário convocar, do panteão grego, xs personagens relacionadxs no título do texto. Clio, filha de Zeus e de Mnemósine (respectivamente líder dxs deusxs do Olimpo e deusa da memória), é uma das nove musas ${ }^{14}$ - e como sabido, é considerada a musa da História, da inteligência e da criatividade. Clio também é conhecida por presidir a eloquência (assim como uma de suas irmãs, Calíope), e aqui, arriscando certa liberdade literária, pode ser considerada musa da oralidade e da história oral.

Mas a eloquência não é dom exclusivo de Clio ou de Calíope. Hermes, filho de Zeus e de Maia (deusa da fecundidade e energia vital), por sua vez, é considerado o deus da comunicação, eloquência, oralidade e hermenêutica. Este, ao se relacionar com Afrodite, deusa do amor, teve uma série de descendentes, dentre elxs, Hermafrodito, ${ }^{15}$ que nascido menino, em 
uma das versões recorrentes do mito, teria se fundido à ninfa Salmacis e se transformado em alguém com características que hoje convencionamos como andróginas ${ }^{16}$ ou bigêneras. ${ }^{17}$ Hermafrodito, na mitologia grega, representava a mescla ou simultaneidade entre os dois sexos/gêneros, não tendo um sexo/ gênero definido. É representado imageticamente como alguém com caracteres estéticos femininos e masculinos.

Se por um lado Hermafrodito pode metaforicamente remeter a pessoas intersexuadas ${ }^{18}$ (e até por isso antigamente tais pessoas serem chamadas de "hermafroditas"), pode também aludir, liricamente, a pessoas transgêneras não-binárias, aquelas que transgridem as expectativas sociais acerca do sexogênero outorgado no nascimento (ou gestação) e que não se sentem totalmente nem mulher e nem homem (em uma ampla espectometria relacionada à não-binariedade de gênero), ${ }^{19}$ ou ainda, a pessoas que não se declaram sócio-politicamente não-binárias como escolha, mas que por determinadas contingências, vivem momentos ou situações não-binárias,${ }^{20}$ de sentimento de inadequação aos binários de gênero constituídos. Hermafrodito parece ser o único caso na mitologia grega de alguém com dois sistemas sexo-gênero simultâneos ${ }^{21}$ - algo aparentemente semelhante ocorria com Tirésias, mas estx não possui os dois sexos-gêneros ao mesmo tempo.

Tirésias, ${ }^{22}$ filhx do pastor Everes e da ninfa Chariclo, foi umx profeta/ profetisa, que, orando no Monte Citorão, vê um casal de serpentes copulando e mata a fêmea: por encanto Tirésias se torna mulher. No mito, depois de sete anos, Tirésias está orando no mesmo monte e vê outro casal de serpentes copulando. Mata o macho e por encanto se torna homem.

Em uma discussão entre Hera e Zeus sobre quem tinha mais prazer nas relações sexuais, mulher ou homem, Tirésias foi chamado para dar seu veredito. Sua resposta foi "se dividirmos o prazer em dez partes, a mulher fica com nove e o homem com uma", irritando Hera, que apostava com Zeus que o homem é quem tinha mais prazer. Irada, Hera cegou Tirésias, e como compensação, Zeus lhe deu o dom da previsão. O que o mito sobre Tirésias não conta é se elx encarou sua transformação de homem em mulher como uma bênção ou como um castigo - o mesmo valendo para sua reconversão de mulher para homem. De todo modo, no mito Tirésias é "abençoadx" com o dom da previsão ao se destransicionar. ${ }^{23}$ Haveria para xs gregxs uma associação entre a suposta dádiva da previsão e a suposta dádiva da masculinidade? É provável. De todo modo, tal parte do mito demonstra um caso de transição de gênero seguida de destransição.

A primeira parte do mito de Tirésias pode nos remeter a pessoas que são outorgadas socialmente em um determinado sistema sexo-gênero no nascimento, e não se adequando às expectativas sociais referentes ao sexogênero designado, elaboram uma determinada engenharia estética para adequar sua imagem à sua identidade ou subjetividade de gênero. ${ }^{24}$ É o caso, por 
exemplo, da pessoa que foi identificada como "menino" ao nascer (ou durante a gestação), e, transgredindo normas relacionadas ao que "é ser menino/homem", se identificará posteriormente como mulher transexual ou como travesti, ${ }^{25}$ muitas vezes realizando procedimentos estéticos para adequarem sua aparência e expressão de gênero à forma como se percebem identitariamente. Já a segunda parte do mito pode aludir à pessoa que destransiciona, ou seja, que fez uma transição de gênero (quer seja apenas subjetiva, quer seja também através de empreendimentos estéticos), mas, por algum motivo (ou vários), resolveu fazer o movimento oposto ao que foi realizado. É o caso, por exemplo, de pessoas que se identificam ex-travestis ou ex-transexuais.

Como vimos, no mito de Tirésias, ele foi designadx homem ao nascer, após 7 anos se tornou mulher (transicionou) e depois de mais 7, se tornou novamente homem (destransicionou). Mas e se, hipoteticamente, elx fizesse a engenharia reversa da destransição, ou seja, retransicionasse, se tornando mais uma vez mulher?

Isso não ocorre no mito grego. Mas na vida real sim. É o caso de pessoas que muitas vezes se declaram ex-ex-travestis. Algumas destas pessoas passam por ministérios evangélicos de conversão de travestis, ficam algum tempo, fazem o processo destravestilizador (ou partes deste) e depois, arrependidas, retornam ao gênero feminino de auto-identificação. Talvez pudéssemos aqui, bem provisoriamente, convencionar metaforicamente tais pessoas como exTirésias, ou ainda, ex-ex-Tirésias (e continuamente, ex-ex-ex-Tirésias e daí por diante, variando de acordo com as experiências de (re/des)transição corporal/ subjetiva/identitária). ${ }^{26}$

E o que ocorreria se esta pessoa, hipoteticamente, após re+des+transicionar, se encontrasse numa situação que fosse não de um entre-lugar identitário mas de um não-lugar? ${ }^{27}$ Se não se visse em mais nenhuma situação legível relacionada aos gêneros constituídos socialmente? É o caso de pessoas que passaram por ministérios de conversão de gente trans* mas não se percebem "bem transicionadas" em nenhum polo. Talvez aqui a metáfora seja a de Hermafrodito, sinalizada acima. É o caso também de pessoas que não passaram por ministérios de conversão, mas que simplesmente não acharam seu lugar às vezes nem um entre-lugar - num mundo que procura definir e determinar lugares de gênero. Tais pessoas, talvez não exatamente por vontade própria, mas por certa contingência do destino, não conseguem se ler em um gênero adequado dentro de uma sociedade generificada.

Tudo isto se relaciona, à propósito, com o tema de minha tese de doutorado. Na mesma, pesquisei - especialmente através do que chamei provisoriamente de etnografia ciborgue e história oral ciborgue ${ }^{28}$ - acerca do que pessoas transgêneras faziam com o que determinados discursos religiosos procuravam fazer delas, observando especialmente dois campos de pesquisa: as igrejas inclusivas ${ }^{29} \mathrm{e}$ as missões evangélicas de "cura e libertação" de travestis. 
Aqui, ainda arriscando "brincar" com as palavras, eu chamaria esta etnografia com história oral realizada de "hermafrodita": assim como Hermafrodito tinha dois sistemas sexo-gêneros concomitantes, a pesquisa foi feita simultaneamente (ou quase) em ambientes off-line e on-line. ${ }^{30}$

Durante a tese fiz dezenas de entrevistas com pessoas transgêneras, (ex-)ex-transgêneras e com pessoas que não se sentiam adequadas a nenhum gênero - por vezes por se sentirem não-binárias e não tendo muitos problemas com isto (ou às vezes nenhum problema); e em alguns casos com pessoas que não viam suas subjetividades (ou identidades) de gênero legítimas ou legíveis: era o caso de pessoas que haviam passado por ministérios de "reversão do homossexualismo" para "deixarem se ser travecos e virarem varões ungidos", ${ }^{31}$ e que muitas vezes não conseguiam mais se identificar, dizendo: "o que eu sou afinal? Não sou homem, não ou travesti, sou o que? Sou um monstro. Você acha que Jesus vai me aceitar no céu desse jeito? Tá doido?". ${ }^{32}$

Esta pesquisa, se ainda pensarmos a partir das metáforas relacionadas à mitologia grega, poderia ser resumida em um encontro de Clio com Hermafrodito e Tirésias - ou ainda, com ex-Tirésias e ex-ex-Tirésias.

Mas a história não para por aí: a pessoa que escreveu a pesquisa também não se percebe como pessoa cisgênera, já tendo se designado em momentos distintos como pessoa não-binária, transgênera, agênera, ${ }^{33}$ poligênera, ${ }^{34}$ pangênera ${ }^{35}$ e queer $^{36}$ - e, novo adendo, sendo extremamente refratária a qualquer tipo de "cura e libertação", "resgate", "restauração" de gênero ou de sexualidade. ${ }^{37}$ Assim, a pesquisa foi realizada por alguém que, além de pesquisadorx, era "nativx" da pesquisa, e que trazia empatia ${ }^{38}$ com outras pessoas transgêneras. Cabe então, indagar:

\section{Mas o que isso reflete da (na) pessoa que escreveu a tese?}

Por se tratar de um trabalho que se conectou à biografia de quem escreveu, talvez possamos questionar: o quanto esta tese é legítima? É adequado tratar de questões que convergem à nossa própria subjetividade ou não? Poderiam filhxs de Clio serem também Hermafrodito ou Tirésias - pesquisadorxs serem nativxs ou partícipes das comunidades pesquisadas? ${ }^{39}$

Neste sentido, e partindo de parte de minhas experiências em campo para tentar esclarecer - ou enegrecer ${ }^{40}$ - algumas das relações entre pesquisadorx e pesquisa quando quem pesquisa é nativx, uma possível questão é: como a Clio que mora dentro dx pesquisadorx que escreve este texto (con)viveram com Tirésias, ex-Tirésias e Hermafrodito (sendo que de algum modo quem escreve se percebe Hermafrodito?)

Quais (alguns d)os desafios epistemológicos que sobrevieram? Falhas? (D)efeitos? Lacunas? Temores, arrepios e choros em campo? ${ }^{41}$ Será que dois campos diferentes (igrejas inclusivas e missões de "resgate e restauração" 
de travestis) receberiam o mesmo tipo de tratamento metodológico e epistemológico ou o mesmo tipo de reação emocional?

Não, não receberam. Em relação ao segundo ponto, eu literalmente chorava de raiva em um caso (quando pesquisava as missões de "cura e libertação" de travestis, e quando ouvia relatos de transfobia ${ }^{42}$ religiosa $^{43} \mathrm{em}$ outros ambientes) e chorava em um mix de alívio, felicidade, empatia e autoidentificação ao ver travestis e transexuais em igrejas inclusivas ${ }^{44}$ ou relatando se sentirem incluídxs em outros locais. E o que esse tipo de reação assimétrica pode indicar sobre nós (e sobre xs outrxs) - ou como nossas pesquisas espelham a nós mesmos (e o quanto isso [não] seria um problema)?

Pensemos a seguir em alguns destes desafios e riscos no espelho de uma pesquisa reflexivamente ativista e engajada.

\section{O que acontece no encontro de Clio com Hermafrodito e Tirésias? E se} Narciso surge no caminho? Nós reflexivos entre xs outrxs e nós

A esta altura quem está lendo o texto deve estar sentindo falta de uma breve explicação sobre outro deus descrito no título do artigo: Narciso. Filho de Cefiso (deus do rio) e da ninfa Liríope, Narciso era conhecido por sua beleza. Antes sde nascer, seu pai e sua mãe consultaram Tirésias afim de saberem o destino da criança: segundo o oráculo, esta teria uma vida longa desde que não visse sua imagem refletida no espelho. Narciso foi alvo do amor de mulheres e homens, e até de ninfas, incluindo uma chamada Eco, a quem menosprezava. A deusa Némesis (versão de Afrodite), para castigá-lo por sua arrogância, o condenou a apaixonar-se por seu reflexo na lagoa de Eco. Narciso, encantado com sua imagem na água, foi definhando até morrer, sendo depois transformado por Afrodite em uma flor, o narciso.

Narciso é assim, paradigma de quem se encanta com seu próprio reflexo - e pode aludir aos nossos trabalhos acadêmicos: seria estes narcísicos? Reflitamos, a partir de contribuições de colegas de outras áreas das ciências humanas (afinal, não seria narcísico uma pessoa historiadora só considerar argumentos de historiadorxs?).

A antropóloga Miriam Pillar Grossi, em um texto intitulado Na busca do "outro", encontra-se a "si mesmo", ${ }^{45}$ explica que a subjetividade dx pesquisadorx, e o seu encontro com quem é pesquisadx, ocupa lugar central no processo de construção de teorias, etnografias e conceitos antropológicos. Sua preocupação neste texto é pensar a "especificidade da relação entre o pesquisador que investiga um objeto similar a ele mesmo e do investigado que interage com o pesquisador". ${ }^{46} \mathrm{O}$ texto encerra com a enunciação: "nunca é demais lembrar que só se encontra o outro, encontrando a si mesmo" e "cada caminho reflete a forma individual e subjetiva do encontro de si mesmo a partir do encontro com o outro". ${ }^{47}$

Para além da questão de encontrar nx outrx a si mesmx, Heloísa Pontes 
amplia a questão, discutindo a delicada posição do sujeito cognoscente que é simultaneamente sujeito e objeto de sua investigação. ${ }^{48} \mathrm{~A}$ autora narra ter sido ao mesmo tempo pesquisadora e militante do movimento feminista, ${ }^{49} \mathrm{e}$ que tal interlocução de saberes provocou alguns problemas, comentando que

tendemos, enquanto antropólogos, a levar ao paroxismo o pressuposto básico do discurso e da prática psicanalítica, qual seja, o de que os outros somos nós - ou, o que vem a dar no mesmo, de que nós somos os outros. A afirmação de Merleau-Ponty - de que a antropologia "não é uma especialidade definida por um objeto particularas sociedades 'primitivas' - é a maneira de pensar que se impõe quando o objeto é ' outro' e que exige a nossa própria transformação" -, embora brilhante para definir a abrangência da disciplina, parece no entanto insuficiente para circunscrever a antropologia que vem sendo feita no Brasil. ${ }^{50}$

Ainda relacionado ao pressuposto de que xs outrxs somos nós e nós somos xs outrxs, Pontes indaga: "como enfrentar a objetividade e os problemas éticos subjacentes a uma pesquisa em que a pesquisadora é parte do objeto que pretende analisar?"51 Para a mesma, a solução está na reflexão meticulosa sobre a construção do objeto de pesquisa por parte de quem pesquisa, ${ }^{52}$ e um movimento "no sentido de proceder a um recuo temporal, analítico e subjetivo em relação ao material recolhido pela pesquisa". ${ }^{53}$

Mas como proceder este recuo quando se trata de um trabalho de história do tempo imediato feito no fervilhar dos acontecimentos - como no caso de uma tese a ser depositada e um campo que foi descrito e (parcialmente) analisado até uma semana antes do depósito? ${ }^{54}$ Talvez a solução (parcial) seja, de inicio, assumir a provisoriedade das reflexões, a instabilidade dos conceitos, e muitas vezes a parcialidade e falta de isenção quando se trata de um trabalho mais engajado.

Estas reflexões podem trazer perguntas: até que ponto (não) somos Narcisos no campo - ou o quanto (não) são nossos trabalhos narcísicos? O quanto não esperamos ver nas pesquisas realizadas as respostas às nossas próprias inquietações, ou às inquietações dos coletivos a que pertencemos ou nos identificamos? Estaríamos sempre fadadxs a algum tipo de espelhamento? Vale a pena riscar ou mesmo quebrar alguns destes espelhos - ou podemos ser agraciadxs com sete anos de azar?

Há mecanismos de necessário controle narcísico? O recuo seria suficiente, ou não necessariamente? O quanto nossos trabalhos potencialmente narcísicos podem funcionar como narcóticos a nos entorpecerem? ${ }^{55}$ Refletiriam, em alguns casos, o individualismo de quem precisa se perceber e se entorpecer 
$\mathrm{dx}$ (nx) outrx? Qual o eco de nossos trabalhos porventura (ou por desventura) narcísicos? Quais as flores semeadas? Estamos olhando nossos reflexos e deixando de olhar x outrx? Seriam as pessoas que estudamos reflexos de nossos alter egos? Projetamos a nós mesmxs nelas? Observamos a nós mesmxs em nossos trabalhos, de modo semelhante ao que indicam as imagens sobre Narciso, a seguir?

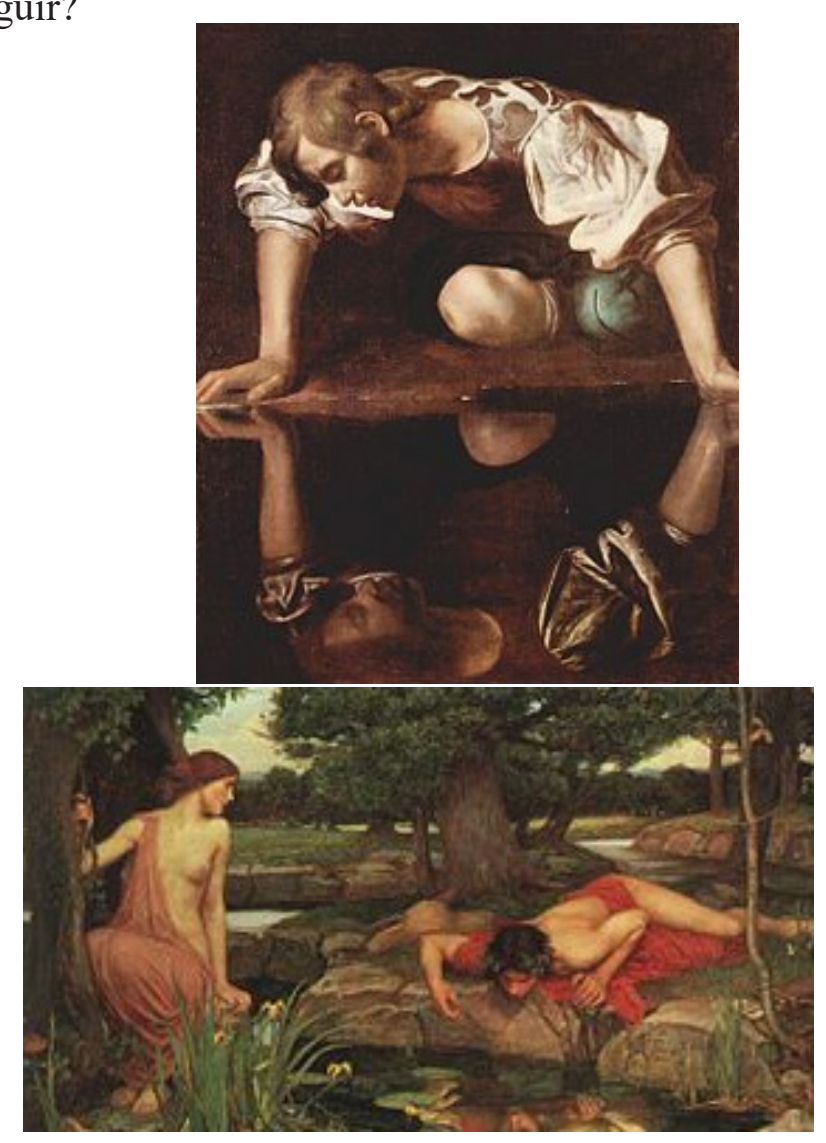

Imagens: Narciso, de Caravaggio (1594-1596); Eco e Narciso, John William Waterhouse (1903)

Quais os problemas e riscos de um trabalho que se torna (ou nasce) narcísico? Quais os limites reflexivos que se interpõem, afinal? Provavelmente o maior dos problemas seja o risco de nos afogarmos no lago das nossas próprias teorias, concepções e expectativas, sem deixar x outrx se expressar livremente e aprendermos a partir de suas próprias ideias e teorias de mundo: muitas vezes protagonizamos o que levamos a campo, relegando a segundo plano as concepções das pessoas nativas sobre si mesmas (ou às vezes sobre a gente).

No espelhamento, estaríamos "iluminando" o campo com nossos pressupostos ao invés de sermos iluminadxs pelo mesmo? Devemos arranhar o espelho - ao menos problematizar tais reflexos de nós nas pesquisas? Ou 
quebrar o espelho de vez - abdicando de encontrar x outrx em nós mesmxs e de encontrar a nós mesmxs nx outrx?

Por outro lado (e não se trata do outro lado do espelho), assim como refletimos o campo e o campo nos reflete, podemos nos deixar afetar/impactar pelo mesmo assim como o afetamos/impactamos - e assumir que o impacto, ainda que assimétrico, pode ser recíproco, assim como possíveis (desejáveis?) transformações.

O maior risco no (do) espelho é provavelmente que, ao pesquisarmos $\mathrm{x}$ outrx, englobemos hierarquicamente estx em nossos próprios termos e conceitos, ao invés de nos (re/des)estruturarmos e aprendermos a partir $\mathrm{dx}$ mesmx. Enfim, não parece ideal que o narciso fique egocentricamente solto no campo (como pode sugerir a foto abaixo), sem convergir nos diálogos necessários.

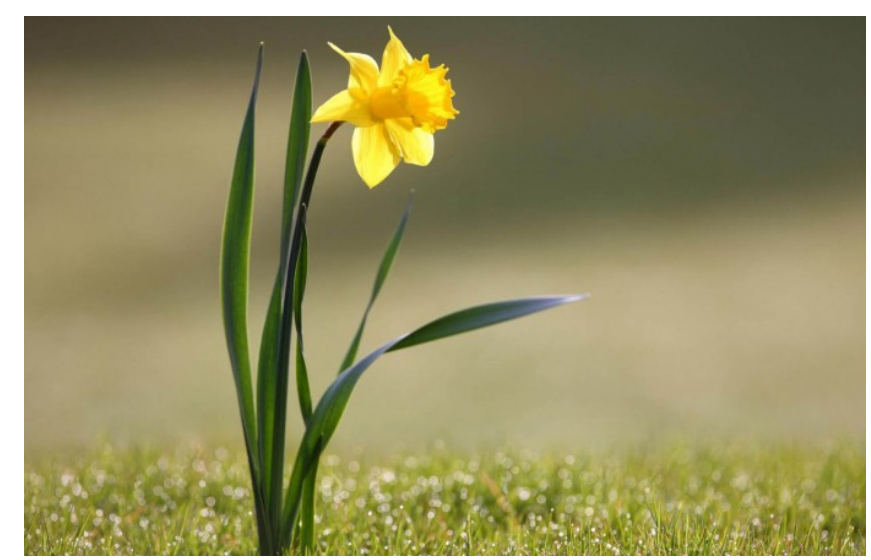

Imagem: Narciso no campo

Neste sentido, pensando na minha pesquisa, poderiam (ex)Tirésias e Hermafrodito afetar Clio - ou o campo moldar novas formas de fazer história oral (ou uma história oral ciborgue e "hermafrodita", misturada em on-line e off-line)? O quanto o Narciso e Hermafrodito dentro de mim reverberaram nos modos como a pesquisa foi realizada?

\section{Alguns reflexos de Narciso na minha pesquisa}

Como dito acima, eu chorei em campo (ou em casa, após retornar do mesmo). Mas eram lágrimas diversas: em igrejas inclusivas, havia uma emoção difusa e as lágrimas salgadas eram mescladas por alívio e certa admiração pelo modo como algumas pessoas transgêneras eram acolhidas (lembro que nem sempre todas eram acolhidas), e às vezes angústia por conta dos relatos escutados. Já nas missões de "cura e libertação", era um choro de descontentamento e infelicidade por conta das narrativas ouvidas, que 
mostravam impactos (in)tensos nas psiquês das pessoas que passavam por estes ambientes.

Estas emoções, ecos de minha própria subjetividade, foram reverberando hermafrodita e narcisicamente na pesquisa, e, definitivamente, não consegui ser menos parcial do que fui, nem nas lágrimas e nem no tratamento das fontes -e apresento a seguir o maior exemplo de fragilidade da pesquisa que fiz.

Como comentei, os campos principais de minha tese foram as igrejas inclusivas e os ministérios de "cura e libertação" de travestis. Após entrevistar pessoas relacionadas ao primeiro campo mencionado, e me sentindo muito mais à vontade, minha predisposição costumava ser a de continuar diálogos em outros fóruns e trabalhar em conjunto, quase em co-autoria, o texto final relacionado à entrevista com as pessoas colaboradoras. Eu costumava sugerir que as pessoas, se lembrando de mais detalhes, me contassem para que estes fossem incorporados no texto, ou que alterassem o mesmo livremente.

De outra forma, e bastante assimetricamente, ao conversar com missionárixs e líderes de ministérios de "cura e libertação" de travestis, minha disposição à continuidade do diálogo era distinta: de modo geral, logo após realizar a entrevista, eu pedia que a pessoa já assinasse o termo de consentimento (muitas vezes à mão, em meu caderno de campo), e não solicitava que a pessoa entrasse em mais detalhes sobre o assunto posteriormente, visto não ter o desejo de continuar conversando com estas pessoas. Além disso, enquanto uma etnografia era feita com satisfação, a outra me causava frustração.

Certamente, isso gerou (d)efeitos na pesquisa realizada. Se por um lado eu estava dispostx a escutar e dialogar de modo mais simétrico e horizontalizado com pessoas que frequentavam igrejas inclusivas (ou com pessoas que haviam passado por missões de "cura" mas que não eram líderes ou missionárias dos mesmos), aprendendo suas concepções de mundo que, de algum modo me faziam perceber a mim mesmx em campo, por outro, minha indisposição, recalcitrância e resistência em relação aos ministérios de "cura" de travestis me impediu ter o mesmo tratamento das fontes e, muito provavelmente, conhecer com mais densidade e profundidade as concepções nativas. Apresento esta fragilidade do trabalho para dar vistas a como nossas pesquisas, por vezes narcísicas, podem moldar tanto os procedimentos como os resultados dos mesmos. Sei que poderia ter tratado as duas fontes e os dois campos de um modo menos parcial, conferindo a ambos o mesmo rigor metodológico de análise, e que a partir de minha seleção, algumas fontes assumiram um discurso de maior autoridade que as outras, dada a relação com a minha própria subjetividade e formas como cada campo me afetava.

Vale realçar que durante a tese, fugi o quanto pude de trabalhar com a questão da reversão de travestis em "homens de Deus". Eu tinha certeza que não seria agradável conhecer estas histórias e que não trabalharia com elas com a "isenção" (se é que isso exista) necessária. Eu fui de alguma maneira 
"seguidx" por este campo, que em determinado momento não mais sussurrava, mas gritava, como se fosse necessário que alguém escrevesse sobre ele (e o que eu menos queria era que fosse eu a escrever). Fui a campo com ideias pré-concebidas de que eram ambientes de discriminação e discurso violento em relação às pessoas transgêneras e ex-transgêneras.

Talvez - narcisicamente - por não me considerar uma pessoa cisgênera, eu não poderia ter uma impressão muito diferente. Chegando lá, e conversando com as pessoas, a minha visão se aprofundou, mas não necessariamente se modificou. Ao contrário, foi reforçada a minha impressão de serem ambientes de discursos violentos direcionados a pessoas vulneráveis sócio-economicamente. Entretanto, já naquela época eu sabia dos riscos narcísicos do campo - e procurei, ao conversar com líderes e missionárixs de "cura" de travestis, compreender suas concepções a partir de seus pontos de vista, e não dos meus pressupostos - mas certamente, isto não se deu da mesma forma em relação ao campo das igrejas inclusivas. E ainda que procurasse de algum modo ser menos parcial, intimamente, ao entrevistar ou conversar com missionárixs e líderes de "cura" de travestis, me sentia numa batalha contra os titãs (não a banda, mas os seres mitológicos gregos). Guardadas as mais que devidas proporções, eu me sentia como se tivesse entrevistado pessoas torturadas (travestis a serem "curadas") e pessoas torturadoras (missionárixs de "cura"). Não consegui realmente estabelecer os recuos necessários, ao que faço minha mea culpa, deste e de outros deslizes em campo.

Assim, assumo que meu trabalho foi mais parcial do que poderia ser e, como Hefesto (deus da tecnologia e de artesãos/ãs), manco. Mas me manquei e assumo que Hermafrodito e Narciso reinaram, impedindo que eu conseguisse dar o mesmo tratamento às fontes, como aliás deveria - ou poderia. ${ }^{56}$

Não pretendo afirmar isso, mas, assim como se diz que "somos todos antropólogos" e "somos todos nativos", ${ }^{57}$ é possível considerarmos, ao menos quem trabalha com história do tempo imediato, a expressão "somos todos narcisos". Enfim, nossos trabalhos talvez estejam mais para Gaia (deusa da Terra) do que para Helios (deus do Sol), ou sejam mais geocêntricos que heliocêntricos - ainda que saibamos que a Terra não é o centro do sistema solar. Mas se o olho é a janela da alma (e a alma a janela do olho) conseguimos fazer algum trabalho (na academia e na vida) que não seja narcoticamente narcísico?

\section{Reflexos inconclusivos}

Ainda sem mudar o foco do olhar, é importante realçar que trabalharmos a partir da reflexão de nós mesmxs e/ou dos coletivos aos quais integramos (e por vezes nos identificamos) não significa, necessariamente, que não devamos ter o cuidado (mais que) necessário com as fontes, fazer um trabalho pautado em princípios éticos, em colaboração com as pessoas pesquisadas, e adotar todos os recuos possíveis. Todos estes procedimentos são fundamentais. Este 
cuidado deve prevalecer justamente por conta dos riscos elencados.

Ao mesmo tempo, isso não significa que devamos nos iludir com a expectativa de fazermos trabalhos "imparciais", ou nos furtar à tarefa e função social de refletirmos as mazelas sociais e atuarmos em prol de uma sociedade mais justa. Assumir um lado (não do espelho, mas da política) é possível e muitas vezes, necessário.

Longe de querer oferecer respostas e "iluminar" alguma coisa, este texto é um exercício de resistência (ou de re-existência), e, novamente aludindo a Tirésias, algumas destas reflexões podem se relacionar a versos da canção: "tô iluminado pra poder cegar, tô ficando cego pra poder guiar", ou "eu tô te explicando pra te confundir, eu tô te confundindo pra te esclarecer". E ainda, sabendo ser este texto um ensaio inconclusivo, "eu to me despedindo pra poder voltar". ${ }^{58}$ Encerrando, deixo perguntas a quem me lê: Vamos continuar refletindo? O trabalho de vocês acha feio o que não é espelho? ${ }^{59}$

\section{NOTAS}

1 MARANHÃO $\mathrm{F}^{\circ}$, Eduardo Meinberg de Albuquerque. (Re/des) conectando gênero e religião. Peregrinações e conversões trans* e ex-trans* em narrativas orais e do Facebook. Tese de Doutorado apresentada ao Programa de Pós Graduação em História Social da Universidade de São Paulo. São Paulo, 2014.

2 Utilizo no texto $x x$ ao final de palavras que podem ser femininas, masculinas ou não-binárias.

3 Utilizo o $e$ ao final de termos generificados marcando minha auto-identificação como pessoa não-binária de gênero.

4 Transgeneridade, neste texto, é entendida como a condição sócio-política de inadequação ou transgressão de expectativas e normas sociais a respeito de determinados sistemas sexo-gênero outorgados no nascimento ou gestação. Não se trata de uma identidade específica, como por exemplo, transexualidade e travestilidade.

5 Ex-transgeneridade é compreendida aqui como o movimento oposto ao da transgeneridade: ocorre quando a pessoa faz uma destransição de gênero, saíndo do gênero transicionado, de auto-identificação anterior, em direção ao gênero definido socialmente em seu nascimento ou gestação a partir da visualização de seus genitais.

6 Ex-ex-transgeneridade é o movimento de retorno ao gênero de auto-identificação após a destransição.

7 A cisgeneridade refere-se ao sentimento de adequação às normas e expectativas de gênero outorgadas no nascimento ou gestação.

$8 \mathrm{O}$ barqueiro Carontes era responsável por transportar as almas de pessoas recém falecidas através dos rios Aqueronte e Estige em direção ao Hades, em um entre-lugares dividido pelo mundo dos vivos e o dos mortos.

9 Éolo era o deus dos ventos na mitologia grega, tanto das brisas suaves como das tempestades e intempéries.

10 No trabalho de campo,quemé@ "nativ@” (ou a/o native)? Não seria@ pesquisador@, muitas vezes, também pesquisad@ pel@s que se supõem “estarem do outro lado"? 
11 História do Tempo Imediato pode ser considerada como aquela realizada no calor dos acontecimentos, em geral sendo enfeixada sob o termo História do Tempo Presente, e história oral consiste, em uma determinada concepção (dentre muitas outras), no conjunto de procedimentos metodológicos que pode envolver, não apenas a realização de entrevistas, mas o projeto, o contato com pessoas a serem entrevistadas, autorização, textualização, transcrição (para algumas pessoas também a transcriação), devolutiva, possível manutenção em acervo e a publicação dos resultados.

12 Uso tais termos de modo irônico, pois, muitas vezes, "vítima" e "algoz" pode ser questão de perspectiva.

13 Hermenêutica, do verbo grego "hermēneuein", termo que deriva de Hermes, deus da eloquência, significa esclarecer, anunciar, interpretar, traduzir ou declarar. Nesta parte do texto, o termo hermenêuticas é utilizado como sinônimo de interpretações.

14 As nove musas são: Calíope (bela voz), musa da eloquência; Clio (proclamadora), da $\mathrm{H}(\mathrm{h})$ istória; Erato (amável), da poesia lírica; Euterpe (doadora dos prazeres), da música; Melpômene (poetisa), da tragédia; Polímnia (a dos muitos hinos), da música ceremonial; Tália (quem faz flores brotar), da comédia; Terpíscore (rodopiante), da dança, e Urânia (celestial), da astrologia e astronomia.

15 Conta o mito, especialmente nas Metamorfoses de Ovídio (OVÍDIO, Metamorfoses, Livro IV, 306-312), que ao atingir quinze anos, Hermafrodito conheceu nos bosques da Cária (próxima ao Halicarnasso, atualmente Bodrum, Turquia) a náiade (ninfa aquática) Salmacis, que enamorada, tomou a iniciativa de seduzi-lo mas foi rejeitada. Pensando que esta havia ido embora, Hermafrodito despiu-se e mergulhou no lago, quando Salmacis entrou n'água e, envolvendo o jovem, o beijou enquanto tocava seu peito. No momento em que Hermafrodito procurava se desvencilhar, Salmacis invocou xs deusxs pedindo que xs mantivessem eternamente conectados. Tendo seu desejo concedido, seus corpos de mesclaram em um corpo só, bigênero ou intersexual. Hermafrodito, envergonhado, amaldiçoou o lago, desejando que todxs que ali se banhassem se tornassem como ele, alguém com os dois sexos-gêneros. Náiades são ninfas aquáticas conhecidas pelos dons de profecia e cura, além da beleza. O caso em que Salmacis investe em relação a alguém com fins de conquistá-lo parece ser atípico: de modo geral, as náiades é que costumavam sofrer assédios.

16 A androginia pode ser considerada como a condição subjetiva em que a pessoa se identifica tanto com a feminilidade como com a masculinidade, comumente com reflexos em sua aparência. A androginia não deve ser confundida com orientação sexual ou interssexualidade. Há pessoas andróginas de qualquer orientação sexual e há pessoas interssexos andróginas e não-andróginas. Pessoas andróginas podem referir sua androginia como expressão de gênero (o que é mais usual) ou identidade de gênero. Androginia também pode referir-se somente à maneira de se vestir, independentemente da expressão ou identidade de gênero da pessoa.

17 A bigeneridade refere-se a pessoas que pertencem simultaneamente ao gênero feminino e ao masculino. Podem performatizar tais gêneros alternativamente (num momento manifestando o masculino, em outro o feminino), sobrepor os gêneros (quando, por exemplo, a interface/ performatividade de gênero é masculina e a identidade de gênero, feminina).

18 A intersexualidade é o conjunto de condições anatômicas e/ou características sexuais primárias ou secundárias que não permitem que a pessoa seja definida claramente como do sistema sexo-corpo-gênero feminino ou masculino. Pessoas interesexos não são necessariamente andróginas, nem bigêneras, nem transgêneras. Geralmente possuem características primárias e/ou secundárias de ambos os sexos/gêneros, como genitais internos e/ou externos, em geral com predominância de um ou outro, e por esta razão nem sempre são designadas claramente 
dentro do sistema sexo-corpo-gênero como mulher ou como homem. Muitas vezes possuem estrutura cromossômica XXY, misturando os cromossomos masculinos XX e os femininos XY. Para informações mais detalhadas, leiam $O$ Sexo dos Anjos: representações e práticas em torno do gerenciamento sociomédico e cotidiano da interssexualidade, de Paula Sandrine Machado (2008).

19 Não-bináries é o termo neutro para pessoas não-binárias, ou que não se encaixam/ enquadram integralmente em nenhum dos gêneros binários, feminino ou masculino. A ampla maioria das pessoas não-binárias $(n-b)$ se considera trans* (ou trans, ou transgênera) por não estar em conformidade com o sistema sexo-gênero outorgado no nascimento (ou na gestação) ainda que não se sintam totalmente encaixados no sistema sexo-gênero "oposto". Por exemplo: a pessoa foi designada "menina" ao nascer mas não se identifica com tal enunciação, ao mesmo tempo em que não se vê como "menino". De modo geral, por não se identificarem com o sexo/gênero "oposto" ao designado ao nascer, não se consideram transexuais. Entretanto, há homens trans, mulheres transexuais e travestis (identidades de gênero costumeiramente entendidas como binárias), que se consideram concomitantemente n-b.Algumes não-bináries se percebem agêneres (sem gênero) ou bigêneres (com dois gêneros, não necessariamente binários), ou nenhum dos dois. Há, dentre muitas equações possíveis, quem se entenda metade menina e metade agênere, ou parte bigênere, parte só menino e parte alguma outra coisa. A abreviatura de não-binárie é $n$ - $b$. Em inglês, abrevia-se enby, algo como não-bi.

20 Além de identidades não-binárias, é possível pensarmos em expressões de gênero nãobinárias e em situações ou biografias não-binárias, inclusive em alguns casos não-voluntárias.

21 Poderiamos, por se tratar de personagem que tem os dois sexos-gênero simultâneos, chamar de Hermafrodit@, Hermafroditx ou outra forma que contemplasse ambos sexos-gêneros. Optei aqui por manter o original Hermafrodito, no masculino, para maior fluidez da leitura.

22 Recomendo o filme Tirésias, que tem uma brasileira e um brasileiro como intérpretes nesta releitura da história dx profeta/profetisa (2003). O filme dirigido por Bertrand Bonello e protagonizado por Clara Choveaux e Thiago Téles apresenta Tirésias como uma transexual brasileira sequestrada e que, privada de hormônios, vai readquirindo aparência masculina. Sobre sua personagem brasileira, Bonello comenta que "no Brasil há muitos transexuais e uma grande presença religiosa, uma convivência entre o profano e o sagrado" (Adivinho Tirésias vira transexual brasileiro em filme francês. Disponível em: http://www1.folha.uol. com.br/folha/ilustrada/ult90u33273.shtml. Acesso em: 20 mar 2014). Referência do filme: TIRÉSIAS. Direção: Bertrand Bonello. França/Canadá: Canal+, Haut et Court, Centre National de la Cinématographie (CNC), 2003 (115 min.).

23 Destransicionar seria o processo de desfazer a transição de gênero. Por exemplo, a pessoa foi outorgada mulher ao nascer, mas se identifica como homem (transhomem, transmasculino, homem trans, dentre outros termos) e faz uma engenharia corporal para adequar sua expressão de gênero à sua identidade de gênero. Na destransição, esta pessoa atua na desconstrução do corpo transgênero (transmasculino) e na reconstrução do corpo cisgênero (feminino).

24 Ressalto que nem toda a pessoa que se declara transexual, travesti ou transgênera passa, necessariamente, por uma adequação estética. A subjetividade ou identidade de gênero se situa na consciência e auto-percepção da pessoa, e não fundamentalmente em sua aparência corporal.

25 Não estou presumindo travestilidade como sinônima de transexualidade: uma é distinta da outra. Ao mesmo tempo, não compreendo transgeneridade como identidade ou subjetividade: é uma condição sócio-política de inadequação ao sistema sexo-gênero outorgado no nascimento ou gestação.

26 Escrevi sobre este assunto, além da tese (2014), em, por exemplo: MARANHÃO Fo ${ }^{\circ}$ Eduardo 
Meinberg de Albuquerque. A Pomba-gira Lady Gaga e a travesti indígena: (Re/des) fazendo gênero no Alto Rio Negro. In: Mouseion (UniLasalle), v. 22, pp. 151-175, 2015; e Sai desse corpo que esse caminho não te pertence! Pessoas trans* e ex-trans* em (re/des)caminhos de gênero, corpo e alma. In: Revista Brasileira de História das Religiões. ANPUH, Ano VIII, n. 24, p. 197-219, Janeiro/Abril de 2016.

27 Situações subjetivas de deslocamentos, ou de estar entre lugares identitários de modo efêmero ou permanente, podem ser pensadas a partir dos entre-lugares de Homi K. Bhabha. Para este, há uma "necessidade de passar além das narrativas de subjetividades originárias e iniciais e de focalizar aqueles momentos ou processos que são produzidos na articulação de diferenças culturais" (BHABHA, Homi K. O local da cultura. Belo Horizonte: Ed. UFMG, 1998, p. 20). Já Marc Augé sinaliza para a relação entre identidade e lugar/não-lugar. A noção de não-lugar está em oposição “à noção sociológica de lugar, associada à Mauss e por toda uma tradição etnológica àquela de cultura localizada no tempo e no espaço” (AUGÉ, Marc. Nãolugares: Introdução a uma antropologia da supermodernidade. São Paulo: Papirus, 1994, p. 36).

28 Denominei provisoriamente de etnografia ciborgue e história oral ciborgue o conjunto de procedimentos que envolvem o trabalho nas esferas on-line e off-line. Um texto que escrevi (no prelo), denominado "Me adiciona? / Pode entrevistar pelo Facebook?” (Re/des)conectando procedimentos operacionais através de etnografia, história oral e observação ciborgues, fala sobre esse assunto.

29 Destaco que, nas igrejas inclusivas (pesquisei, na cidade de São Paulo, a Igreja da Comunidade Metropolitana (ICM), a Igreja Cristã Evangelho Para Todos (ICEPT), a Comunidade Cristã Nova Esperança Internacional (CCNEI), e especialmente seu ministério Séfora's de Travestis e Transexuais), conversei especialmente com pessoas transgêneras, especialmente travestis e mulheres transexuais. Não utilizo neste texto metáforas da mitologia grega que aludam a estas pessoas, mas sim, a pessoas ex-transgêneras, ex-ex-transgêneras, e em situações não-binárias de gênero (não confundir situações contingenciais não-binárias de gênero com subjetividades e identidades políticas não-binárias).

30 Realizei entrevistas especialmente através do Facebook.

31 Escutei este termo, e outros semelhantes, durante entrevistas com pessoas relacionadas à "cura e libertação" da travestilidade e da transexualidade. Realço que uso tal termo entre aspas por não entender haver uma "cura e libertação" de tais identidades / subjetividades, mesmo porque nenhuma das duas (assim como as demais condições transgêneras) pode ser considerada condição patológica - nem tampouco deveria ser psiquiatrizável, demonizável ou pecadologizável.

32 Fragmento de entrevista no Acampamona, acampamento evangélico que tinha por objetivo "curar e libertar" travestis do "homossexualismo radical".

33 A ageneridade pode ser considerada uma identidade de gênero não-binária - ou a falta de gênero, dependendo da concepção. Ao pé da letra, agêneras são pessoas que não possuem ou não reconhecem possuir gênero. Também costumam ser denominadas gendervoid (vazie/a/o de gênero) ou genderless (sem gênero).

34 Poligeneridade pode ser entendida como um conjunto amplo formado por diversas identidades ou subjetividades de gênero, mas não incluindo todas, como no caso da pangeneridade.

35 A pangeneridade pode ser considerada um conjunto de subjetividades ou de identidades de gênero. Seria o conjunto amplo formado por todos os gêneros existentes, não necessariamente de modo simultâneo 
36 Originalmente, o termo queer, em inglês, é equivalente a xingamentos como viado, tarado, depravado, ou ainda estranho, esquisito. Apropriado e ressignificado pela teoria queer, o termo pode ser entendido como transgressor/transgressivo. Em geral serve como guarda-chuva para diversas minorias políticas associadas a identidades de gênero, expressões de gênero (o termo genderqueer é uma extensão de queer) e orientações sexuais e afetivas. O termo identifica a teoria queer, pessoas queer, e ainda estilos de vida, concepções, ideias, figurinos, etc. A maior referência na teoria queer é Judith Butler, seguida de Beatriz Preciado e outr@s autor@s.

A teoria queer é o conjunto de ideias que procura desconstruir o caráter supostamente fixo das identidades de gênero, e se fundamenta especialmente na obra Problemas de gênero, de Butler, e em conceitos constantes na mesma, como performatividade de gênero e atos performativos, por sua vez baseados em autores como Derrida e Austin. A teoria queer tem na clássica frase de Beauvoir ("ninguém nasce mulher, torna-se") uma inspiração para pensar que "ninguém nasce homem, cis, trans, pan, poli, etc, torna-se". Tal teoria pode ser utilizada para (re)pensar quaisquer classificações/rotulações/marcações de identidade e diferença, como as religiosas, as culturais, as raciais, etc.

37 Lembrando que identidade de gênero e orientação sexual, assim como expressão de gênero e ou ainda orientação afetiva, não são coisas equivalentes.

38 Podemos entender empatia como o colocar-se na situação da outra pessoa (não sendo a pessoa e nem vivendo o que ela vive), mas procurando compreender seus sentimentos e afetos. E como bem explica Cristina Scheibe Wolff, Lynn Hunt demonstra que "a própria noção de direitos humanos foi sendo construída através do sentimento de "empatia", que implicava na ideia de que os "outros", os sem-propriedade, os judeus, os escravos, os prisioneiros e até, progressivamente, as mulheres, teriam sentimentos e emoções semelhantes aos sujeitos políticos" (WOLFF, Cristina Scheibe. Pedaços de alma: emoções e gênero nos discursos da resistência. In: Revista de Estudos Feministas, Florianópolis, 2015, p. 978).

39 Outro exemplo de natividade está em quem estuda o ciberespaço: certamente se trata de alguém pessoa nativa, que se utiliza do ciber como internauta que é. Quem estuda gênero, (in) certamente tem um gênero, ou seja, pesquisa a partir de sua própria localização de gênero (ou em alguns casos, através de entre-lugares e/ou não-lugares generificados: há pessoas agêneras, bigêneras, poligêneras, pangêneras, etc).

40 Interessa pensar que utilizamos adjetivos associados à claridade para "iluminar" as coisas, mas como a linguagem é dinâmica e merece ao menos às vezes ser subvertida para refletirmos sobre as fronteiras e limites conceituais da própria língua, aqui podemos conceber o termo enegrecer como sinônimo e não antônimo de iluminar ou esclarecer, ou melhor, como forma de entendermos melhor o assunto e estimular diálogos. Ao mesmo tempo, é plausível que este texto mais confunda ("enegreça") que esclareça alguma coisa, no sentido da música Tô, de Tom Zé: "eu tô te explicando pra te confundir, Eu tô te confundindo pra te esclarecer" (1976).

41 Trato desta questão dos choros em campo mais especificamente em outro texto em construção e em breve no prelo, intitulado Eu, ciborgue: (re/des) fazendo gênero, lágrima e pesquisa entre afetos, ferrugens e diamantes.

42 Transfobia pode ser entendida como a aversão, pavor, repulsa a pessoas transgêneras em geral. A pessoa transfóbica pode tornar-se violenta simbólica ou/e fisicamente em relação à travestis, transexuais, crossdressers, andrógines, não-bináries, e demais pessoas com variabilidades não cisgêneras. O termo transfobia pode se relacionar especificamente à travestifobia, por exemplo, ou a outras formas de intolerâncias/violências/discriminações a pessoas cujos sexos/gêneros são considerados socialmente divergentes ou abjetas. 
43 A transfobia religiosa seria a aversão, ódio ou repulsa a pessoas transgêneras fundamentada em concepções religiosas, que regem que tais pessoas são, por exemplo, "filhas do diabo", "o próprio diabo" e "consagradas ao capeta". A transfobia religiosa costuma se basear no que chamei na tese (2014) de teologia cishet/psi/spi, um conjunto de concepções teológicas, fundamentalistas e reacionárias, fundadas na cis-heteronormatividade, em pressupostos das áreas psi e no maniqueísmo e dicotomia típicos da teologia da batalha espiritual.

44 Como demonstro na tese, nem toda igreja inclusiva (e nem todo terreiro de religião de matriz afro-brasileira) se mostra sempre inclusiva - assim como nem toda filial de igrejas fundamentalistas é sempre fundamentalista ou excludente. Varia de casa de santo pra casa de santo, de filial de igreja pra filial de igreja.

45 GROSSI, Miriam Pillar. Na busca do "outro" encontra-se a "si mesmo". In: GROSSI, Miriam et alli. Trabalho de Campo e Subjetividade, Florianópolis, PPGAS, 1998.

46 GROSSI, 1992, p. 8.

47 GROSSI, 1992, p. 14.

48 PONTES, Heloísa. Inventário sob forma de fichário. Paixão e compaixão: militância e objetividade na pesquisa antropológica. Revista de Antropologia, São Paulo, USP, v.36, 1993. p. $123-135$.

49 Pontes realizou sua pesquisa na década de 1980.

50 PONTES, 1993, p. 132.

51 PONTES, 1993, p. 124.

52 A autora escreve a partir da antropologia e da sociologia, mas provavelmente suas premissas podem cabem às demais áreas das ciências humanas.

53 PONTES, 1993, p. 131

54 Um exemplo esteve em Josi, uma das principais personagens da tese: no início de minha pesquisa (2010), Josi declarava-se travesti, garota de programa, e era cantora/secretária da Igreja da Comunidade Metropolitana (ICM/SP). Durante a tese, passou a definir-se como mulher transexual, e a trabalhar em telemarketing. Há uma semana do depósito da tese, Josi comentou ter retornado ao candomblé, religião à qual fez parte anos antes. Tal informação fez com que eu precisasse referi-la, e inclui em uma das últimas páginas do trabalho: "há uma semana de depósito da tese, meados de dezembro, Josi posta em seu Facebook que resolveu fazer nova mudança em sua vida: retornar ao candomblé. Esta informação pode ter colocado@1eitor@atordoad@: afinal, Josi está desde a gênese da tese, sendo lembrada na dedicatória, e abre nossos trabalhos com sua narrativa "disseram que eu era o Diabo e que Deus ia me matar mas eu não acreditei”, o que a vinculava à ICMSP e a uma filiação cristã inclusiva. E agora, se reconverte ao candomblé? Será o apocalipse? Não,prezad@ leitor@, não é - o novo caminho de luz de Josi só nos lembra como momentos como este acionam nosso carrossel identitário e nos fazem gente-constituíd@s de agência para definirmos por e para nós mesm@s possíveis giros e mudanças de (per)cursos. Qualquer fluxo identitário que se faça, se é de pleno desejo da pessoa não-patologizada/pecadologizada/demonizada, e para seu bem, parodiando um célebre apóstolo televisivo, "é pra aplaudir de pé” (2014, p. 651).

55 Aliás, a palavra grega narke significa entorpecido/a, e dá origem a vocábulos como narcótico, narcisismo e narcísico.

56 Talvez Dioniso, considerado deus patrono das travestis e hermafroditas, estivesse em algum lugar soprando etilicamente quais os caminhos que eu deveria seguir. 
57 Viveiros de Castro lembra que "somos todos antropólogos, mas ninguém é antropólogo do mesmo jeito: "está muito bem que Giddens afirme que "todos os atores sociais [...] são teóricos sociais', mas a frase é vazia se as técnicas de teorização têm pouca coisa em comum" (Strathern, 1987, p. 30-31)" (VIVEIROS DE CASTRO, Eduardo. O nativo relativo. Mana, vol.8, N.1, Rio de Janeiro, abril 2002, p. 141). Além de lembrar que "ninguém é antropólogo do mesmo jeito" (aqui podemos pensar que ninguém é oralista, historiador@ ou pesquisador@ da mesma maneira), Viveiros de Castro reforça que "ninguém é nativo o tempo todo" (VIVEIROS DE CASTRO, 2002, p. 141).

58 ZÉ, Tom. Tô. In: Estudando o samba. Rio de Janeiro: Polysom, 1976.

59 Dedico este texto a todas as pessoas transgêneras, ex-transgêneras, ex-ex-transgêneras e em outras situações não-cisgêneras que gentil e generosamente compartilharam experiências comigo. Dedico também a todas as pessoas que me supervisionaram ou orientaram trabalhos: Joana Maria Pedro, pela supervisão do Pós-Doc; José Carlos Sebe Bom Meihy, pela orientação do Doutorado; Artur Cesar Isaia e Márcia Ramos de Oliveira, pela co-orientação e orientação do Mestrado; a Cristina Sheibe Wolff, pelas discussões proporcionadas no LEGH/UFSC e na disciplina de Subjetividades e Relações de Poder, em que estagiei no Pós-Doc, e às/aos colegas do laboratório e da disciplina referidxs. Gratidão.

Artigo recebido em abril de 2016. Aceito em julho de 2016. 